\title{
Clinical Trial Investigator Regulatory Agreement
}

National Cancer Institute

\section{Source}

National Cancer Institute. Clinical Trial Investigator Regulatory Agreement. NCI

Thesaurus. Code C115477.

A legally binding document containing the accession by any/all investig ators of a clinical trial that all trial activities will conform fully to all regulations as set forth by the law, or any other supervisory authority. 